\title{
Can All Benign Gallbladder Diseases be Managed Laparoscopically?
}

\author{
Ratan $\mathrm{MEH}^{\mathrm{a}}$, Alam H ${ }^{\mathrm{b}}$, Karim MA ${ }^{\mathrm{c}}$
}

\begin{abstract}
Background: Laparoscopic cholecystectomy (LC) operation is widely practiced in gallbladder diseases. However, controversy persists for LC in acute gall bladder disease, as risk of complications appears to be greater than open procedurel. This study presents the outcome of LCs performed as the first option of treatment in benign chronic as well as acute gall bladder diseases.

Methods: Twelve hundred consecutive patients of gall bladder disease, both acute and chronic, underwent cholecystectomies by a single surgeon using standard four port technique. Age, sex, diabetes, prior abdominal procedures, per-operative findings, additional procedure done and complications directly related to surgical technique were evaluated.

Results: The laparoscopic approach was attempted in all patients of this series. Success rate was $99.58 \%$. Non diabetic patients presented much earlier for surgery then diabetic patients. About one third (31.4\%) of the patients had acute cholecystitis and its complications and none of them required conversion. Conversion rate was seen among those with long history of gall stone and fibrosed contracted gall bladder at ultrasonography. There were three bile duct injury cases among which two were managed laparoscopically and one needed conversion. Most of the patients (94.5\%) were discharged within 20 hours of surgery. There was one mortality $(0.08 \%)$ in this series.
\end{abstract}

Conclusion: LC has proved to be an effective and safe day case surgical procedure for benign gall bladder pathologies and their complications. It provides much benefits with low complication and conversion in experienced hands.

Key words: Laparoscopy, cholecystectomy, benign gall bladder diseases.

(BIRDEM Med J 2018; 8(1): 35-41)

\section{Introduction}

Patients with symptomatic gallbladder diseases are usually advised to undergo cholecystectomy to relieve symptoms and avoid complications. ${ }^{1}$ Surgery is also

\section{Author Information}

a. Dr. Md. Ezharul Haque Ratan, Associate professor, Surgery, Ibrahim Medical College and BIRDEM General Hospital, Shahbagh, Dhaka-1000, Bangladesh

b. Dr. Hasina Alam, FCPS (General Surgery), Registrar, Surgery, Ibrahim Medical College and BIRDEM, General Hospital, Shahbagh, Dhaka-1000, Bangladesh

c. Dr. Md. Abdul Karim, Resident Medical officer BIRDEM General Hospital, Shahbagh, Dhaka-1000, Bangladesh

Address of correspondence: Dr.Md. Ezharul Haque Ratan, MS (General Surgery), Associate professor, Surgery, Ibrahim Medical College and BIRDEM, Room no-445, BIRDEM General Hospital, Shahbagh, Dhaka-1000, Bangladesh, Tel-01711172547, Emailezhar65@gmail.com

Received: October 29, 2016 adviced in cholesterosis (Strawberry gallbladder), cholesterol polyposis of gall-bladder and cholecystitis glandularis proliferans. ${ }^{2,3}$ Prophylactic cholecystectomy may be considered for diabetic patients, patients with congenital haemolytic anaemia, if stones are multiple and likely to cause complication such as acute pancreatitis, if stone is single and large which is more likely to cause acute cholecystitis. ${ }^{1,3}$ LC is now the preferred method to remove a diseased gallbladder. ${ }^{4}$ Laparoscopic procedure may not be successful in grossly obese individuals and patients with multiple previous abdominal surgery. ${ }^{1}$ Controversy persists for LC in acute gall bladder disease, as risk of complications appears to be greater than open procedure. ${ }^{1}$ This study presents the outcome of 1200 consecutive LCs performed from March 2008 to December 2015. 


\section{Methods}

Twelve hundred consequtive LCs were performed by a single surgeon from March 2008 to December 2015, in BIRDEM general hospital. All patients having benign gallbladder pathology were included for LC. Preoperative evaluation consisted of serum alanine aminotransferase, alkaline phosphatase and abdominal ultrasound. Abdominal CT or MRCP scan, endoscopic retrograde cholangiopancreatography(ERCP), serum amylase and serum lipase were done in selective cases. Patients with symptoms suggestive of peptic ulcer disease or gastrointestinal reflux disease were evaluated preoperatively by upper gastrointestinal endoscopy. LC was performed using the standard four puncture technique. Pneumoperitonium was established by placement of a Veress needle umbilically. Patients having prior abdominal surgery involving umbilical region had the veress needle inserted into left subcostal area in midclavicular line. $5 \mathrm{~mm}$ trocars were placed in the right anterior axillary line and the right midclavicular line and $10 \mathrm{~mm}$ trocars were placed in the epigastrium and the umbilicus. Blunt dissection and limited electrocautery was used to identify the cystic duct and artery. Anterior and lateral traction were applied to the infundibulum of the gallbladder during this dissection. The cystic duct and artery were ligated with titanium or hemoclips or absorbable suture transfixation and transected. The gallbladder was dissected from the liver bed in a retrograde fashion using electrocautery and blunt dissection. The gallbladder was removed through the umbilical port. Simple subhepatic drains were used infrequently and at the discretion of the attending surgeon. Fascial closure of the umbilical port with an absorbable suture was performed in all the patients. All skin incisions were reapproximated with an absorbable subcuticular suture. Factors evaluated include age, indication, conversion rates to open cholecystectomy, hospital stay, intraoperative and postoperative complications and mortality.

\section{Results}

LC was attempted in 1200 patients, 744(62\%) female and 456(38\%) male. Among them $842(70.17 \%)$ were diabetic and 358(29.83\%) were nondiabetic. Mean age was 49.9 years and ranged from 7 to 93 years. Patients' demography is demonstrated in Table-I.

Table I. Demography of Patients Undergoing Laparoscopic Cholecystectomy

Number-1200

$\begin{array}{lll}\text { Male } & 456(38 \%)-\text { Diabetic-342 }(75 \%), & \text { Non Diabetic- } 119(26.1 \%) \\ \text { Female } & 744(62 \%)-\text { Diabetic-500 }(67.2 \%), & \text { Non Diabetic- } 239(32.1 \%)\end{array}$

Age:- Mean- 49.9 years

$\begin{array}{lll}\text { Male } & \text { Diabetic- } 49.9 \pm 6.2 \text { years, } & \text { Non-diabetic- 49.9-6.8 years } \\ \text { Female } & \text { Diabetic- } 49.9 \pm 1.7 \text { years, } & \text { Nondiabetic- 49.9-9.1years }\end{array}$

Age Range:-
Male-
Diabetic- (30-90) years,
Nondiabetic- (7-93) years
Female-
Diabetic- $(25-90)$ years,
Nondiabetic- (14-77) years

LC was performed after evaluation of the patient at out patient department, on same day or day before surgery. All patients were admitted in the afternoon and the surgery was performed in the evening hours or night. The indications for LC are summarized in Table-II. 


\begin{tabular}{ll}
$\begin{array}{ll}\text { Table II. Indications for } \\
\text { Cholecystectomy }(\mathrm{n}=1200)\end{array}$ & Laparoscopic \\
\hline $\begin{array}{ll}\text { Acute Gall Bladder Disease } \\
\text { Acute cholecystitis with cholelithiasis }\end{array}$ & $-349(29.1 \%)$ \\
Acute acalculous cholecystitis & $-14(1.2 \%)$ \\
Gangrenous cholecystitis & $-9(0.8 \%)$ \\
Gangrene with perforated gallbladder $-5(0.4 \%)$ \\
Chronic Gall Bladder Disease & $-823(68.6 \%)$ \\
Chronic cholecystitis with cholelithiasis $-694(57.8 \%)$ \\
Silent gall stone in diabetics & $-38(3.2 \%)$ \\
Gall stone with post ERCP state & $-23(1.9 \%)$ \\
Gall-bladder polyp & $-54(4.5 \%)$ \\
Gall stone with cholecystoduodenal fistula $-7(0.6 \%)$ \\
Gall stone acute pancreatitis & $-4(0.3 \%)$ \\
Worm in the gallbladder & $-3(0.2 \%)$ \\
\hline
\end{tabular}

Five patients $(0.42 \%$.) had to be converted to open cholecystectomy(Table-III) . Contracted thick walled gall-bladder by preoperative image study were correlated with an increased rate of procedure conversion. Conversion was not needed in any of the acute cholecystitis cases. Conversions to open procedure were due to adhesions precluding a safe laparoscopic approach.

Table III. Indications for Conversion to Open Cholecystectomy $(\mathrm{n}=5)$

\begin{tabular}{lc}
\hline Indication & No. of patients (\%) \\
\hline $\begin{array}{l}\text { Chronic cholecystitis with } \\
\text { pericholecystic adhesion }\end{array}$ & $02(40)$ \\
Failure to identify anatomy of & $01(20 \%)$ \\
biliary tree & \\
Common bile duct transection & $01(20 \%)$ \\
Instrument failure & $01(20 \%)$ \\
\hline
\end{tabular}

A total of $192(16 \%)$ patients had prior abdominal surgery(Table-IV). All of them had successful laparoscopic cholecystectomy. Careful adhesiolysis and structure identification before cliping was the key to success.
Table IV. Prior Abdominal Procedures in Patients Undergoing Laparoscopic Cholecystectomy (n-192)

Procedure

No of Patients(\%)

Caesarean section

$112(58.3 \%)$

Abdominal hysterectomy

$47(24.5 \%)$

Appendicectomy

$16(8.3 \%)$

Gastric procedure

$5(2.6 \%)$

Hernia (ventral,incisional)

$4(2.1 \%)$

Exploratory laparotomy

$4(2.1 \%)$

Diagnostic laparotomy

$4(2.1 \%)$

*7 patients had multiple procedures

Additional abdominal procedures during laparoscopic cholecystectomy were performed in $93(7.75 \%)$ patients(Table-V). Among 11 liver biopsies 7 were suspected as cirrhosis of the liver of which 6 were confirmed at histopathology and one case was fatty infiltration. One suspected malignancy revealed haemangioma at histopathology. All 5 peritoneal biopsies were suspected as tuberculosis and confirmed at histopathology. Additional laparoscopic procedure with laparoscopic cholecystectomy like appendicectomy, ovarian cystectomy, hernioplasty with preperitoneal mesh did not pose any morbidity and adverse effect on hospital stay or post operative visit.

Table V. Additional Procedure Performed During Laparoscopic Cholecystectomy ( $\mathrm{n}=93$ )

\begin{tabular}{lc}
\hline Procedure & No of Patients(\%) \\
\hline Ovarian cystectomy & $20(21.5 \%)$ \\
Appendicectomy & $18(19.3 \%)$ \\
Adhesiolysis & $17(18.3 \%)$ \\
Liver and / or peritonial biopsy & $16(17.2 \%)$ \\
Cholecystoduodenal fistula repair & $7(7.5 \%)$ \\
Hernia : umbilical & $5(5.3 \%)$ \\
Hernia : inguinal & $3(3.2 \%)$ \\
Haemorrhoidectomy & $2(2.2 \%)$ \\
Lateral sphincterotomy & $2(2.2 \%)$ \\
Hernia : incisional & $1(1.1 \%)$ \\
Para-aortic lymph node biopsy & $1(1.1 \%)$ \\
Bilateral tubal ligation & $1(1.1 \%)$ \\
\hline
\end{tabular}


Incidental pathologies found during $\mathrm{LC}$ were as in Table VI. Nine patients $(0.75 \%)$ unexpectedly had adenocarcinoma of the gall-bladder at histopathology (incidental carcinoma). All of them were refered to hepatobiliary pancreatic surgeon.

Table VI. Incidental Pathologies Found During Laparoscopic Cholecystectomy $(\mathrm{n}=1200)$

\begin{tabular}{lc}
\hline Pathology & No of Patients(\%) \\
\hline Cirrhosis of the liver & $16(1.3 \%)$ \\
Haemangioma of the liver & $10(0.8 \%)$ \\
Gallbladder Malignancy & $9(0.75 \%)$ \\
Cholecystododenal fistula & $7(0.58 \%)$ \\
Tuberculous peritonitis & $5(0.41 \%)$ \\
Tubercular hepatitis & $4(0.33 \%)$ \\
\hline
\end{tabular}

There were $13(1.1 \%)$ intraoperative complications (Table - VII) among successful LC cases. Cases with hepatic duct injury were due to dense adhesions between common hepatic duct and medially placed Hartmann's pouch with impacted stone. Both injury were small and managed laparoscopically with 4-0 vicryl suture (interrupted) and subhepatic drain. One case of duct of Luschka was noticed peroperatively and was managed with figur of eight stitch and subhepatc drain. Metal(titanium) clip was placed to common bile duct in one case, noticed soon after application and removed immedietly. All the difficult to control bleeding was managed by gelatin sponge compression and subhepaic drain. All cases recovered uneventfully except common bile duct clip patient. He required biliary bypass 9 months after LC due to mild chronic hyperbilirubinemia $(1.7 \mathrm{mg} / \mathrm{dl})$ with chronic pain. Another patient developed mild jaundce in the 4th POD, he recovered without intervention while awaiting ERCP.

Table VII. Inraoperative Complications during Laparoscopic Cholecystectomy $(\mathrm{n}=1200)$

\begin{tabular}{lc}
\hline Complications & No of Patients(\%) \\
\hline Excessive bleeding from & $9(0.75 \%)$ \\
gallbladder fossa & \\
Common hepatic duct injury & $2(0.17 \%)$ \\
Duct of Luschka & $1(0.08 \%)$ \\
Bile duct clipping & $1(0.08 \%)$ \\
\hline
\end{tabular}

Post operative complications occured in 10 patients and are summarized (Table-VIII). One patient with severe acute cholecystitis with a wide cystic duct ligated with vicryl, developed bile leakage in the post operative period. The discharge gradually decreased and dried up at 6th POD. Two other had gangrene of the gallbladder where cystic duct could not be identified and clipped, developed bile leak in subhepatic drain, gradually decreased and stoped at 7 th and 9th POD respectively.One patient developed mild jaundice on 4th POD and recovred while awaiting ERCP. A lady developed anterior axillary line port discharge at 12 weeks after operation, culture was negative and biopsy from margin revealed granulomatous inflammation suggestive of tuberculosis. She was treated and cured with standard anti TB treatment. All 3 umbilical port hernia cases were offered laparoscopic repair.

Table VIII. Postoperative Complications after Laparoscopic Cholecystectomy $(\mathrm{n}=1200)$

\begin{tabular}{lc}
\hline Complications & No of Patients(\%) \\
\hline Post operative Bile leak & $3(0.25 \%)$ \\
Port hernia & $3(0.25 \%)$ \\
Mild chronic diarrhoea & $2(0.17 \%)$ \\
Jaundice & $1(0.08 \%)$ \\
Port site tuberculosis & $1(0.08 \%)$ \\
\hline
\end{tabular}

One lady, 65 years old, died on the 2nd post-operative day (POD). She had diabetes mellitus, hypertension and underwent LC for sympyomatic chronic cholecystitis. She was discharged in the afternoon of 1 st POD. She developed severe chest pain at evening of 2nd POD, brought to emergency department after 20 minutes drive, where she was found dead probably due to acute coronary syndrome.

Most of the patients, 1134 cases (94.5\%), were discharged within 20 hours of surgery and the rest, $1168(97.3 \%)$ patients, within 48 hours of surgery.

\section{Discussion}

Open cholecystectomy has mostly been replaced by laparoscopic procedure for excision of diseased gall 
bladder over couple of decades ago ${ }^{5}$. Randomized trials show significant difference with regard to pain, hospital stay and post operative recovery comparing LC to open procedure $^{4}$. Knowing some definite advantages of laparoscopic procedure, it seems to be unjustified to subject patients to open cholecystectomy for trial purpose $^{6}$. In this retrospective series, all patient appearing with benign gall-bladder pathology for which cholecystectomy was indicated, were subject to LC. Female patients $(62 \%)$ outnumbered male patients(38\%) among both diabetic and non diabetic cases. Female patients presented much earlier for surgery in comparison to male patients and interestingly non diabetic patient presented much earlier for surgery than diabetics both in male and female.

Symptomatic cholelithiasis appeared to be the most common diagnosis among which a significant number of patients had acute cholecystis and its complications. Among gallbladder polyps most were chesterol polyposis. Chlecystoduodenal fistula was found only during initial few years predominatly and very rarely thereafter probably because more cholecystectomies are done now before such complication developes. Decreased conversion rate is probably due to the same reason. This series did not include any case of billiary dyskinesia due to lack of diagnostic facility (cholecystokinin augmented hepatobiliary scanning to document a poorly contracting gallbladder).

During the early years, acute cholecystitis was considered a relative contraindication to $\mathrm{LC}$ due to higher perioperative morbidity and conversion rates 10 . Now a days, conversion rates have come down to $10 \%$ from $33 \%$ and perioperative morbidity rates have become comparable to those of open cholecystectomy for acute cholecystitis ${ }^{11,12}$. In this series, LC was performed successfully in all cases of acute cholecystitis and its complication. This study supports the view that despite high technical challenge, LC can be performed safely in acute cholecystitis by an experienced laparoscopist ${ }^{13}$. The conversion rate in this series was $0.42 \%$ which is much lower than that found in other reports ${ }^{4}$. Contracted thick walled gall-bladder by preoperative image study were correlated with an increased rate of procedure conversion. All of the conversions needed in this series were due to chronic dense pericholecystic adhesion leading to failure of identification of anatomy at the triangle of Calot.
Conversions to an open procedure were due to adhesions precluding a safe laparoscopic approach. None of the acute cholecystitis cases needed conversion. None of the female patients needed conversion.

Veress needle and trocar insertion leads to the most common complications of laparoscopic surgery ${ }^{14}$. These injuries are more common in patients who had previous abdominal operations ${ }^{15}$. Veress needle puncture at a site away from previous surgery or an open technique (Hasson) would have been a safer means of preventing such injuries ${ }^{16,17}$. In this series, left subcostal area in mid clavicular line was the most favoured site of veress needle puncture in patients having previous surgery. Fortunately, there was no pneumoperitoneum related complications in this series.

Intraoperative cholangiogram was not done in this series due to lack of a functional choledochoscope. Instead we assessed our patients with preoperative USG, ALT, Alkaline phosphatase, gamma-glutamyl transpeptidase and bilirubin. Patients with suspected choledocholithiasis, underwent ERCP with stone extraction followed by LC on the next day $(0.08 \%)$. Only one patient returned with symptomatic choledocholithiasis in early post operative period and got relieved spontaneusly while awaiting for ERCP. This was much less than other series had reported.

Peroperative leakage from acute inflammed gallbladder was not associated with increased incidence of abdominal abscess, provided patients were given appropriate antibiotics and operation site irrigation, compared to those patients with intact gallbladder. In this series, all cases of perforation, bile leak, stone and sludge spillage were managed by removal of stone in a 'glove bag', aspiration of sludge and bile, followed by copious irrigation with normal saline, initial broad spectrum antibiotic coverage followed by specific antibiotic according to culture and sensitivity reports and placement of right subhepatic drain. There was no incidence of intraabdominal abscess or peritonitis in this series.

Injury to the billiary tree continues to be a significant complication during laparoscopic cholecystectomy ${ }^{4}$. However comparable billiary injury rates between laparoscopic and open cholecystectomy are also demonstrated by some large series ${ }^{5,18,19} \cdot$ In this series, bile duct related complications were $0.33 \%$. Five 
procedures were converted including one bile duct transection. Several studies identified male sex and acute cholecystitis as independent predictors of procedure conversion during laparoscopic cholecystectomy ${ }^{22-24}$. Our finding revealed male sex and comlicated gallbladder disease, especially extensive pericholecystic adhesions and fibrosis at Calot's region, were associated with increased procedure conversion rate. Thirteen patients $(1.1 \%)$ experienced intra-operarive complications. Our complications rate is much lower than those in 2 large scale studies focusing on complication after $\mathrm{LC}^{20,21}$ Port hernias are well known complication following laparoscopic surgery ${ }^{4}$ In a review article the overall incidence was $1.7 \% 25$. In the current series, 3 patients $(0.25 \%)$ returned with port site hernia , 18 to 30 months after surgery, all at umbilical port.

There are limitations of the study .First, a retrospective study is the weakness of this series. Second, the study was performed in a tertiary care hospital which deals with most of the diabetic patients of the country. Strength of the study is inclusion of all cases with benign gallbladder disease irrespective of clinical state or image findings. So it provides useful information on "real world" clinical practice of LC.

\section{Conclusion}

The leap from open cholecystectomy to laparoscopic version had substantial benefits including better cosmesis, much reduced pain, hospital stay as low as a day case and return to work in days. These benefits are associated with increased risk of vascular, gut, and major biliary tract injury. However, these complication rates came down over couple of decades experience. Now a days, $\mathrm{LC}$ is an effective and safe procedure for all benign gall-bladder disease including acute cholecystitis and its complications with low rates of complications, conversion, morbidity and mortality in experienced hands.

Conflict of interest: Nothing to declare.

\section{References}

1. Garden OJ. The liver and billiary tract. In Garden OJ, Brandbury AW, Forsy. Principles and Practice of Surgery. 4th edition. Churchill Livingstone: Edinburgh, London, New york,Philadelphia, St.Louis, Sydney, Toranto; 2002:262-310.

2. Thompson JN, Appleton SG. Laparoscopic billiary surgery. In Kirk RM. General surgical Operations. 5th edition. Churchill Livingstone: Edinburgh, London, New york, Oxford, Philadelphia, St. Louis, Sydney, Toranto; 2006:304315 .
3. Conlon K. The gallbladder and bile ducts. In Norman S,Christopher W, Bulstrode JK, Ronam P, Connel O. Bailey and Love's Short practice of surgery.26th edition. CRC Press: UK; 2013:1097-1117.

4. Comitalo JB. Laparoscopic Cholecystectomy and newer techniques of gallbladder removal.JSLS. 2012;16:406-412.

5. Litwin DE, Cahan MA. Laparoscopic cholecystectomy. Surg Clin North Am. 2008;88:1295-1313.

6. Neugebauer E, Troidl H, Spangenberger w, Dietrich A, Lefering A. Conventional versus laparoscopic cholecystectomy and the randomized controlled trial cholecystectomy Study Group. Brit J Surg. 1991;78:150-154.

7. Azevedo JL, Azevedo OC, Miyahira SA. Injuries caused by veress needle insertion for creation of pneumoperitoneum: A systematic literature review. Surg Endosc. 2009;23:14281432.

8. Adamsen S, Hansen OH, Funch-Jensen P, Schulze S, Stage JG, Wara P, Bile duct injury during laparoscopic cholecystectomy: A prospective nationwide series. J Am Coll Surg. 1997; 184:571-578.

9. Way LW, Steward L, Gantert W. Causes and prevention of laparoscopic bile duct injuries. Ann Surg. 2003;237:460-469.

10. Flowers JA, Bailey RW, Zucker KA. Laproscopic management of acute cholecystitis: The Baltimore experience. AM J Surg. 1991;161:388-392.

11. Bakr AA, Khalil ME, Esmat GE. Acute cholecystitis is an indication for laparoscopic cholecystectomy: a prospective Study. JSLS. 1997;1:119-123.

12. Fonts PR, Nectoux M, Eilers RJ, Chem Em,Rieder CE. Is acute cholecystitis a contraindication for laparoscopic cholecystectomy? Int Sur. 1998;83:28-30.

13. Hashizume M, Sugimachi K, MacFadyen BV. The clinical management and results of surgery for acute cholecystitis. Semin Laparosc Surg. 1998;5:2-8.

14. Hashizume M, Sugimachi K. Needle and trocar injury during laparoscopic surgey in Japan. Surg Endosc. 1997;11:11981201.

15. Mathews BD, Williams GB. Laparoscopic cholecystectomy in an academic hospital: Evaluation of changes in perioperative outcomes. JSLS. 1999;3:9-17.

16. Poole GH, Frizelle FA. Modifications to the Hasson technique. Aust N Z J Surg. 1996;66:770.

17. Gersin KS, Heniford BT, Arca MJ, Ponsky JL. Alternative site entry for laparoscopy in patients with previous abdominal surgery. J Laparoendosc Surg Adv Surg Tech. 1998;8: 125-130.

18. Misra M, Schiff J, Rendon G,Rothschild J, Schwaitzberg S. Laparoscopic cholecystectomy after the learning curve: What should we expect? Surg Endosc. 2005;19:1266-71. 
19. Tantia O, Jain M, Khanna S, Sen B. Iatrogenic biliary injury: 13305 cholecystectomies experienced by a single surgical team over more than 13 years. Surg Endosc. 2008;22:107786.

20. Murphy MM, Shah SA, Simons JP. Predicting major complications after laparoscopic cholecystectomy: A simple risk score. J Gastrointest Surg. 2009;13:1929-36.

21. Giger UF, Michel JM, Opitz I. Risk factors for perioperative complications in patients undergoing laparoscopic cholecystectomy: Analysis of 22,953 consecutive cases from the Swiss Asociation of Laparoscopic and Thoracoscopic Surgery database. J Am CollSurg. 2006;203:723-28.
22. Donkervoort SC,Dijksman LM. de nes LC. Outcome of laparoscopic cholecystectomy conversion: Is the surgeon's selection needed? Surg Endosc. 2012;26:2360-6.

23. Lipman JM, Claridge JA, Haridas M. Preoperative findings predict conversion from laparoscopic to opencholecystectomy. Surgery 2007; 142:556-63.

24. Tang B, Cuschieri A. Conversion duiring laparoscopic cholecystectomy: Risk factors and effects on patients outcome. J Gastrointest Surg 2006;10:1081-91.25.

25. Bunting DM. Port site hernia following laparoscopic cholecystectomy. JSLS 2010;4:490-7. 